\title{
Incidence of Medication Errors in the Use of Biotech Medicines in a Paediatric Hospital Setting
}

\author{
D. C. MANZANARES* AND A. N. RODRÍGUEZ
}

Faculty of Pharmacy, Autonomous University of the State of Morelos, University Avenue 1001, Chamilpa, 62209 Cuernavaca, Mor. National Institute of Pediatrics, Insurgentes Sur 3700 Letra C, Insurgentes Cuicuilco, 04530 Mexico City, Mexico

\section{Manzanares and Rodríguez: Medication Errors in Biotech Medicines}

\begin{abstract}
The paediatric population is more susceptible to medication errors due to factors such as weight, body surface, immaturity of the enzymatic system to metabolize and excrete drugs, and inability to communicate any sign or negative symptom related to a medication. Currently technological advances confront us with new situations or ethical conflicts, the twenty-first century is considered as the century of biotechnology, stem cells, cloning, gene therapy, new drugs, advances not yet adapted to paediatric clinical practice and valued as a relevant factor causing error. Based on case reports on the use and management of biotech medicines, scientific approach was made to understand in depth the problems faced by the medication system, which directly impacts the patients. The objective of the present work was to document, analyse and evaluate medication errors during the use and management of biotech medicines in the paediatric population treated in a highly specialized hospital from September 2017 to April 2018. Prospective, observational design whose main variable is the medication error including potential errors. The taxonomy of the National Coordinating Council for Medication Error Reporting and Prevention was used. The study was carried out for 24 weeks in the medical specialties of oncology, haematology and immunology, as well as in the respective outpatient areas. Three hundred and fifty follow-ups were selected in the use and management of biotech medicines, found $\mathbf{1 0 8 5}$ medication errors. The prevalence of measurement errors is, insufficient monitoring of the medication with $35 \%$; wrong dose with $19 \%$, wrong frequency and time of administration, with 14.7 and $8.5 \%$ respectively, for preparation, handling and conditioning is $6.3 \%$ and wrong medication with $6.6 \%$. The data generated would allow the design and implementation of strategies to strengthen the use and safe management of biotech medicines.
\end{abstract}

Key words: Biotech medicines, medication errors, paediatric patients

Safety of the patient is an essential component in the quality of the healthcare systems, organizations at the international level such as the World Health Organization, the Panamerican Health Organization, the European Council and the institutions in the European Union that have worked on diverse initiatives and promoted numerous studies highlighting the one on the prevalence of adverse effects in Latin-American Hospitals (Study IBEAS) considered as the first study carried out in Latin America in order to measure the adverse events in hospitals, revealing that $8.23 \%$ of the adverse events have a direct relationship with the use of medication, these data have served to elaborate strategic lines and implement interventions oriented towards prevention or mitigation of the unnecessary damage associated with medication use $\mathrm{e}^{[1-3]}$.

*Address for correspondence

E-mail: davidcamachomanzanares@gmail.com
The processes of selection, acquisition, prescription, validation, dispensation, administration and control of medications imply multiple interactions with activities of elevated risk of causing errors. Medication errors are frequent, seldom reported and their prevention poses a challenge to the health institutions; they occur for several reasons from prolonged work hours, to complex processes and they are independent of skill, knowledge or expertise ${ }^{[4]}$. The terminology utilized for the negative effects produced by medications is not unified thus causing confusion, it is convenient

This is an open access article distributed under the terms of the Creative Commons Attribution-NonCommercial-ShareAlike 3.0 License, which allows others to remix, tweak, and build upon the work non-commercially, as long as the author is credited and the new creations are licensed under the identical terms

Accepted 28 September 2019

Revised 29 June 2019

Received 14 April 2019 Indian J Pharm Sci 2019;81(6):1053-1061 
to clarify the terms used, emphasizing that there is no consensus in that regard. The National Patient Safety Agency defines a medication error as "any incident in which there was an error in the process of prescription, distribution, preparation, administration and supervision, independently if the damage occurred or is possible to occur". The National Coordinating Council for Medication Error Reporting and Prevention (NCCMERP) defines error as "any preventable incident that may cause damage to the patient or give rise to an inappropriate utilization of medications, when these are under the control of health professionals, the patient or consumer ${ }^{[5] "}$.

New therapies and innovative medicines that are added to the therapeutic arsenal confront us with new situations or ethical conflicts that affect the safety of the patients, these technological advances have allowed to consider this century as the century of biotechnology, stem cells, cloning, gene therapy, new drugs, advances not yet adapted to the clinical practice and valued as a relevant factor causing errors.

The biotech medicines are proteins that have been made from a living cell (bacteria, yeast, animal, vegetable or insect cell) or from a living organism (transgenic animals) using recombinant DNA techniques or hybridoma technology (monoclonal antibodies) ${ }^{[6,7]}$. Their biological activity depends on the biological process and the quality of the medication system implemented in the health service; it is essential that a cold chain network be used for storage and conservation which guarantees the maintenance or their activity, specific requirement must be complied with for the manipulation, delivery, and preparation, prior to their administration ${ }^{[8-11]}$. The common denominator of biotech medicines is their elevated cost and the growing impact they have on the invoicing of health services which must see to their sustainability and long term viability ${ }^{[11]}$.

The joint commission estimates that 7000 deaths occur annually in all of the patient populations in hospital centres in the United States ${ }^{[12]}$. In hospital environments medication errors are common ${ }^{[13]}$; having an incidence rate 3 times higher in paediatric populations and potentially more harmful as compared to an adult population. The factors which increase risk are, weight, body surface and the immaturity of the enzymatic system, which affect their capacity to metabolize and excrete medications and their inability to communicate if they suffer an adverse effect, which precludes their early detection ${ }^{[14]}$. Dosages in paediatric medications are based on body weight thus requiring a dose calculation which may lead to dosage errors. The incorrect dose is the medication error with a greater report incidence ${ }^{[15]}$. Other reports state that more than half of the medication errors are produced during the prescription phase (49\%) or the transcription phase (11\%) of the process of use of medications ${ }^{[16,17]}$. It is important to generate data on the use and handling of biotech medicines for the paediatric area, which needs specific investigation and decisions that require extreme caution ${ }^{[18,19]}$. The objective of this investigation was to document, analyse and evaluate the medication errors during the use and handling of biotech medicines on the paediatric population in a high-specialty hospital.

\section{MATERIALS AND METHODS}

A systematic review based on the patient-interventioncomparison-outcomes methodology was carried out in order to identify studies on the use of medications in paediatric populations and the medication errors of biotech medicines identified in clinical practice, by performing a qualitative or quantitative synthesis of those studies in order to take them into account as references. The review was carried out through the following browsers, Cochrane, Medline, and PubMed. The keywords used were, paediatric patients, biotech medicines, medication errors; no evidence was found that studies relating to these 3 variables had been carried out before ${ }^{[20-22]}$.

This is an observational, cohort, prospective and crosssectional study in the medication system of a paediatric hospital, the main variable is the medication error related to the use and handling of biotech medicines. Process variables such as errors in prescription, transcription, preparation, dispensing, administration, follow-up, storage and acquisition were considered. Secondary variables relating to the number of patients reached, type of error, consequences and seriousness have been included, as well as incidents with the potential of causing error.

\section{Study population and data collection:}

The study was carried out in a paediatric third level hospital that admits patients from all regions of the country. The study lasted a period of $24 \mathrm{w}$ in the clinical services of oncology, haematology and immunology in hospitalized paediatric patients/population and their respective ambulatory care units. Intensive care unit patients were not included. The incidence for each group was, hospitalized paediatric patients- $55 \%$ and ambulatory paediatric patients- $45 \%$. 
It also included the area of ambulatory chemotherapy and short stay immunotherapy, these were chosen based on the hospital's annual report ${ }^{[23]}$. A sample of 350 follow-ups of the medication system (interrelated processes whose objective is the use of medications in a safe, appropriate and efficient manner) was selected. It includes prescription, transcription, preparation, dispensation, administration, follow-up and acquisition of the biotech medicines in a daily fashion during the morning and night shifts.

The institutional format, pharmacotherapeutic profile was used for recording the data, the required information was: active substance, indication, administration schedule (dose interval between doses, starting date and conclusion) pharmaceutical form, prescription motive, preparation conditions and storage.

The actual use conditions were analysed along with the recommended ones, based on the institutional medications catalog, the medications catalog of the general health council ${ }^{[24]}$, the handbook of medical prescriptions Lexicom ${ }^{[25]}$ and the electronic data base Micromedex ${ }^{[26,27]}$. A data base was drawn up using Microsoft Office Professional Excel Plus 2016.

The main researcher was allowed full access to each area of the medication system, general warehouses, preparation areas, administrative area, access to the clinical and electronic file, nursing area and to accompany in the process of applying medications.

\section{Variables:}

The identification and reporting of medication errors was done in an observational manner in the paediatric patients and in each medication process, the activities were supported by the health personnel (pharmacist, doctor and nurse). The information was completed by means of electronic file, nursing sheets for hospitalized paediatric patients/population, in the case of ambulatory patients, we had access to the areas where the medication was applied and the entire process was observed until the application, the follow-up data were completed in the subsequent visits.

It required that the principal investigator to review medical records, nursing care sheets, and physician instructions in order to complete follow-up data. The reference taken for the definition, evaluation and classification of error was that of the NCCMERP ${ }^{[28]}$ and the good practices guide regarding recording, codification, reporting and evaluation of medication errors of the European Medications Agency
EMA/762563/2014. A work team was formed to evaluate the medication errors, it consisted of specialist physicians, pharmacist, resident physicians, nurses, risk manager, and a representative of the management team for the resolution of cases, and to characterize the medication errors as well as settling discrepancies of opinion in their classification. According to their nature, errors were classified as, wrong medication that include inappropriate selection of the medicine, wrong medication, previous history of allergy, contraindicated medication, inappropriate medication for the patient due to his age or clinical condition and therapeutic duplication; failure to indicate dose of medication such as failure in the prescription, transcription, dispensation and administration; incorrect dose that may include higher than the correct dose or extra dose; wrong administration frequency, wrong pharmaceutical form, error in the preparation or handling or conditioning, wrong administration, route of administration, wrong rate of administration, wrong administration time, wrong patient, incorrect duration of treatment either greater or lower, lack of treatment follow-up that include, lack of clinical revision, analysis and interactions; deteriorated medication, patient non-compliance and others ${ }^{[29]}$.

\section{Definition of results and statistical analysis:}

The statistical analysis was carried out using the statistics software IBN SPSS version 25 (SPSS, Inc. Chicago, IL, USA) by means of descriptive statistics. The qualitative variables were expressed via absolute frequencies and percentages, the quantitative variables were described by measures of central tendency, arithmetic mean (Kolmogórov-Smirnov test), dispersion and standard deviation. The statistical significance was defined as a value of $\mathrm{p} \leq 0.05$ and the confidence interval of $95 \%$ (CI $95 \%)$.

\section{Ethical aspects:}

The study was presented to the general management, the education area and heads of services of medical areas. The principal investigator submitted the project for evaluation and approval to the ethics and investigation committee of the high-specialty hospital, with a registration number 048/2016 with a duration of $20 \mathrm{mo}$. The follow-up was carried out by the pharmacist and was based according to the reports of New Delhi and Tokyo and good practices in pharmacy ${ }^{[30]}$. During the duration of the project the privacy of the information was guaranteed in an atmosphere of cordiality, considering the voluntary participation of the health personnel and taking into account respect, benefit and fair treatment 
according to the Belmont report and the declaration of Helsink $i^{[31,32]}$ as well as to the laws related to research of the Health Department in Mexico ${ }^{[33]}$.

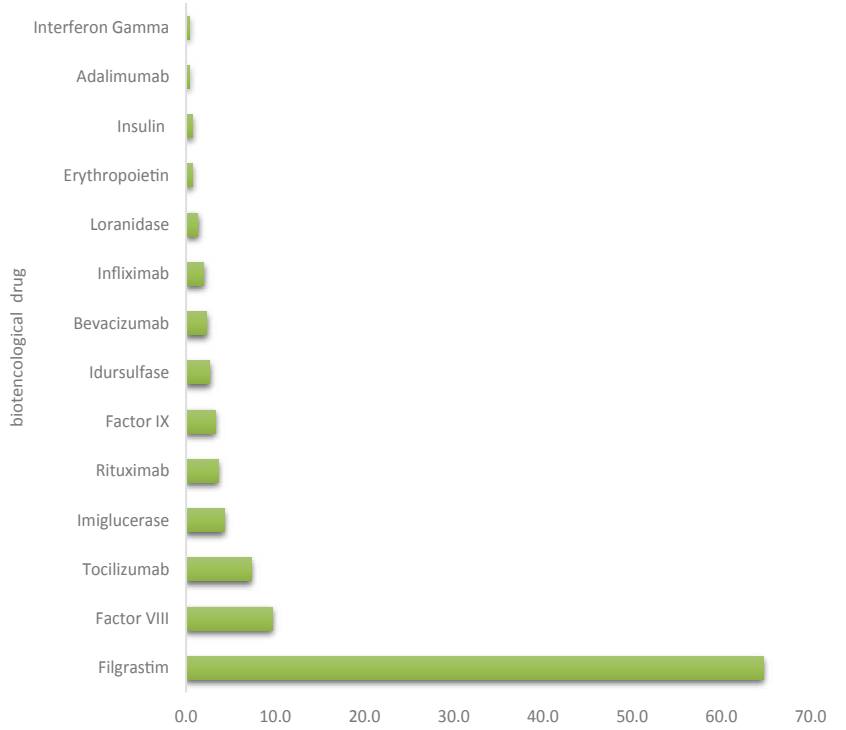

Fig. 1: Most widely used biotech medicines

\section{RESULTS AND DISCUSSION}

The study was conducted in a paediatric population in which the gender distribution was $67 \%$ male and $33 \%$ female, the ages ranged from new born (younger than $28 \mathrm{~d}$ ), $1.64 \%$, to lactating (less than 1 y) $15.7 \%$, preschool ( 1 to $5 \mathrm{y}$ old) $21.31 \%$, school age ( 5 to $13 \mathrm{y}$ old) $27.87 \%$, and teenagers (13 a 18 y old) $32.79 \%$, respectively ${ }^{[34]}$. The medications with higher incidence of medication errors were, filgrastim $64.7 \%$, factor VIII $9.7 \%$, tocilizumab $7.3 \%$, imiglucerase $4.3 \%$, rituximab $3.7 \%$, factor IX $3.3 \%$, idursulfase $2.7 \%$, bevacizumab $2.3 \%$, infliximab $2.0 \%$, loranizase $1.3 \%$, adalimunab and gamma interferon less than $1 \%$ (fig. 1).

Globally, 2789 adverse effects were documented from a professional practice that produces or may produce medication errors in the use and handling of biotech medicines in a paediatric population; identifying the proximate causes and system failures that have contributed to their occurrence. By determining the

\section{TABLE 1: ACTIVITIES WITH THE POTENTIAL TO PRODUCE MEDICATION ERRORS}

\begin{tabular}{|c|c|c|}
\hline Area in the medication system & Detected incidents & $\%$ \\
\hline & $\begin{array}{c}\text { Medical Indication (as a document) } \\
\text { Indication by trade name of the MBT } \\
\text { Illegible or unclear writing. } \\
\text { Omission or error of dose/route/infusion rate/administration schedule } \\
\text { Verbal indication } \\
\text { Omission of information about allergies and/or precautions for the patient. } \\
\text { Medical Indication (as a medical act) }\end{array}$ & \\
\hline Prescription & $\begin{array}{c}\text { Incorrect choice of MBT according to the patient's pathology or } \\
\text { inappropriate use } \\
\text { Omission of the prescription of the MBT } \\
\text { Prescription of MBT with interactions between them }\end{array}$ & $29.5 \%$ \\
\hline Transcription & $\begin{array}{l}\text { Incorrect interpretation of } \mathrm{MBT} / \text { dose/route/dosing interval } \\
\text { Order error from the nursing center to the pharmacy storage }\end{array}$ & $3.7 \%$ \\
\hline & $\begin{array}{l}\text { There is no aseptic preparation area } \\
\text { Inadequate hand washing for drug preparation }\end{array}$ & \\
\hline Preparation & $\begin{array}{l}\text { Incorrect labeling of the medication } \\
\text { There is no compatibility check }\end{array}$ & $22.1 \%$ \\
\hline Dispensation & $\begin{array}{c}\text { Double prescription } \\
\text { Delivery of a different MBT than prescribed, or dose or concentration } \\
\text { Omission of delivery of some MBT } \\
\text { Incorrect delivery of the requested quantity } \\
\text { Sending the order for the wrong patient }\end{array}$ & $1.6 \%$ \\
\hline & $\begin{array}{c}\text { Error in the schedule } \\
\text { Administration of a different MBT to the patient } \\
\text { Error in the dose and the route }\end{array}$ & \\
\hline Administration & $\begin{array}{l}\text { Error in dilution } \\
\text { Omission of the administration }\end{array}$ & $19.6 \%$ \\
\hline Storage & $\begin{array}{l}\text { Lack of expiration control } \\
\text { Inadequate storage conditions or lack of control in them } \\
\text { Incorrect, confusing or disorderly location } \\
\text { Lack of stock }\end{array}$ & $11.5 \%$ \\
\hline Follow-up & $\begin{array}{c}\text { Incomplete anthropometric, physiological and metabolic data in Kardex in the } \\
\text { infirmary. Incomplete file or medical indications } \\
\text { Failure to record relevant patient data, ADR }\end{array}$ & $11.8 \%$ \\
\hline Purchase & MBT that are used, but not in the basic list & $0.30 \%$ \\
\hline
\end{tabular}

Stock: set of biotech medicines that are previously purchased and stored until they are used. Kardex: registration of chronological information of the patient in an organized manner. MBT: biotech medicines, ADR: adverse drug reaction 
error causing incidents in each phase, and based on the relevant process, we obtained the following data as shown in Table 1. The prescription process stands out with $29.5 \%$, the more frequent incidents were: unclear writing, incomplete information on the administration rate of the medication, failure to inform about allergies, or prescriptions without verifying drug interactions. The process of preparation represents $22.1 \%$ of the incidents, highlighting areas that are not suitable to ensure good medicine preparation practices, insufficient sources of information to consult incompatibilities between medicines-solutions and incomplete data on the labelling of the medications. In the administration process, non-compliance with the administration schedules was documented, imprecise dosage and incorrect infusion rate; accounting for $19.5 \%$, the follow-up process represented $11.8 \%$, additionally incomplete anthropometric, physiological or metabolic data were documented, incomplete relevant data such as the presence of a previous ADR was also observed.

The storage process represented $11.5 \%$ of the incidents, resulting from the lack of equipment needed for their conservation, also lack of knowledge of handling such as adequate temperature control and exposure to light are worth mentioning ${ }^{[35]}$.

The classification into medication errors is based on the Spanish adaptation of the NCCMERP classification, the total number of medication errors associated with the use and management of biotech drugs was 1085 in a total of 300 patients, which means an incidence rate of 3.61 errors per patient (Tables 1-3). The higher prevalence was found in the categories of insufficient monitoring of medication (35\%); incorrect dose $(19 \%)$, frequency $(14.7 \%)$, wrong administration time $(8.5 \%)$, preparation, manipulation and conditioning

TABLE 2: TAXONOMY-BASED MEDICATION ERRORS FROM THE NATIONAL COORDINATING COUNCIL FOR MEDICATION ERROR REPORTING AND PREVENTION (NCCMERP)

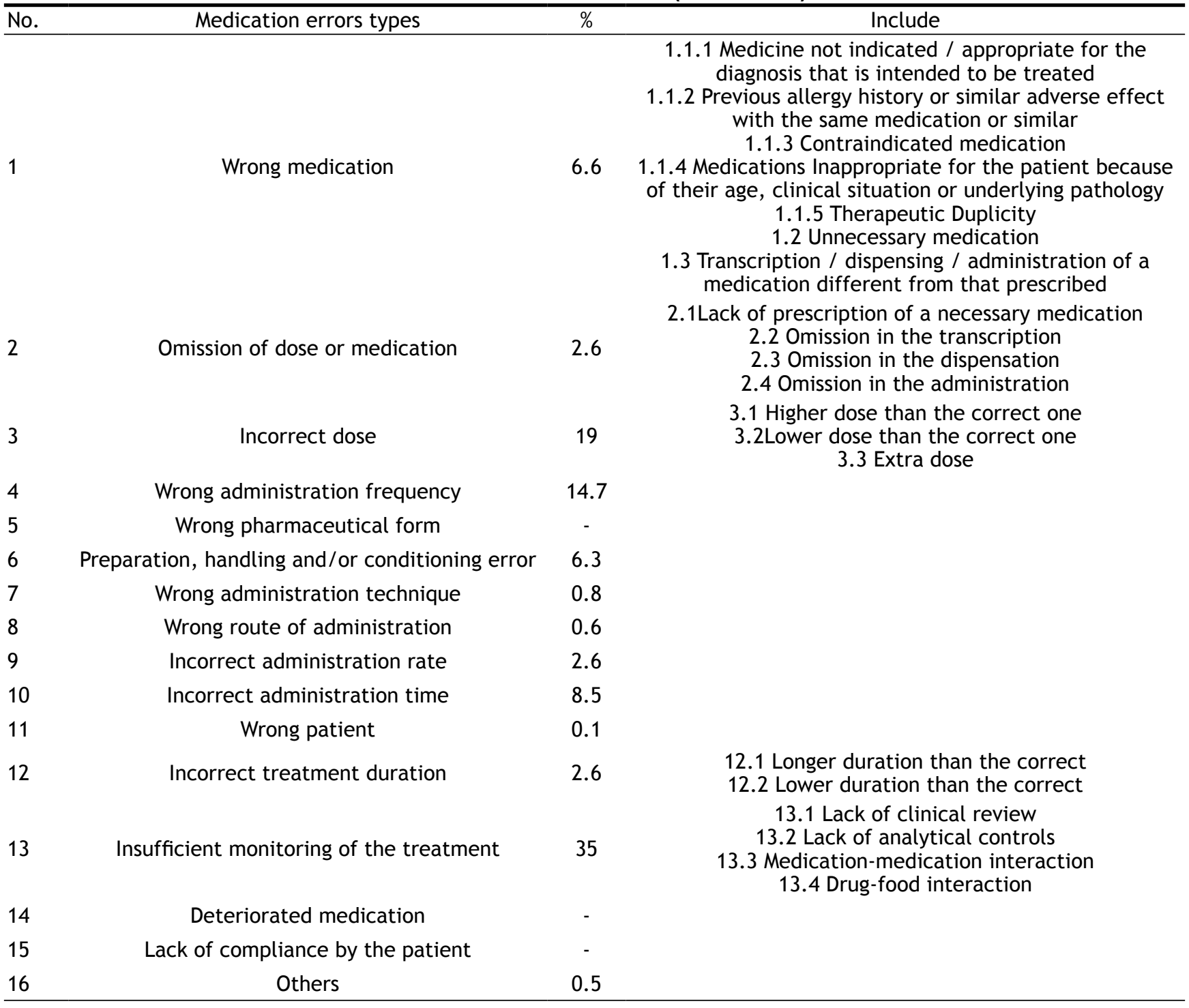


TABLE 3: DESCRIPTIVE STATISTICS OF THE CLASSIFICATION OF MEDICATION ERRORS IN BIOTECH MEDICINES

\begin{tabular}{|c|c|c|c|c|c|c|c|c|c|c|c|c|}
\hline \multicolumn{13}{|c|}{ Descriptive statistics of medication errors } \\
\hline $\begin{array}{l}\text { Categories of medication } \\
\text { errors }\end{array}$ & 1 & 2 & 3 & 4 & 6 & 7 & 8 & 9 & 10 & 12 & 13 & 15 \\
\hline $\mathrm{n}$ & 126 & 50 & 360 & 280 & 120 & 15 & 12 & 50 & 162 & 50 & 665 & 3 \\
\hline Mean & 5 & 10 & 14 & 17 & 19 & 20 & 21 & 22 & 23 & 26 & 29 & 34 \\
\hline Standard error of mean & 0.16 & 0.21 & 0.04 & 0.00 & 0.00 & 0.00 & 0.00 & 0.00 & 0.00 & 0.12 & 0.04 & 0.00 \\
\hline Mode & 5 & 8 & 15 & 17 & 19 & 20 & 21 & 22 & 23 & 25 & 28 & 34 \\
\hline Standard deviation & 1.81 & 1.51 & 0.77 & 0.00 & 0.00 & 0.00 & 0.00 & 0.00 & 0.00 & 0.88 & 1.02 & 0.00 \\
\hline Variance & 3.29 & 2.27 & 0.59 & 0.00 & 0.00 & 0.00 & 0.00 & 0.00 & 0.00 & 0.78 & 1.03 & 0.00 \\
\hline \multicolumn{6}{|c|}{ 1. Wrong medication } & \multicolumn{7}{|c|}{ 9. Wrong administration rate } \\
\hline \multicolumn{6}{|c|}{ 2. Omission of dose or medication } & \multicolumn{7}{|c|}{ 10. Incorrect administration time } \\
\hline \multicolumn{6}{|c|}{ 3. Incorrect dose } & \multicolumn{7}{|c|}{ 11. Wrong patient } \\
\hline \multicolumn{6}{|c|}{ 4. Wrong administration frequency } & \multicolumn{7}{|c|}{ 12. Incorrect duration of treatment } \\
\hline \multicolumn{6}{|c|}{ 5. Wrong pharmaceutical form } & \multicolumn{7}{|c|}{ 13. Insufficient monitoring of treatment } \\
\hline \multicolumn{6}{|c|}{ 6. Preparation, handling and / or conditioning error } & \multicolumn{7}{|c|}{ 14. Damaged medication } \\
\hline \multicolumn{6}{|c|}{ 7. Incorrect administration technique } & \multicolumn{7}{|c|}{ 15. Lack of compliance by the patient } \\
\hline \multicolumn{4}{|c|}{ 8. Flawed administration route } & & & \multicolumn{7}{|c|}{ 16. Others } \\
\hline
\end{tabular}

Medication errors types (Spanish adaptation of the classification of the NCCMERP). The types of medication errors $(5,14$ and 16$)$ are not included in Table 3 due to the absence of cases in these categories

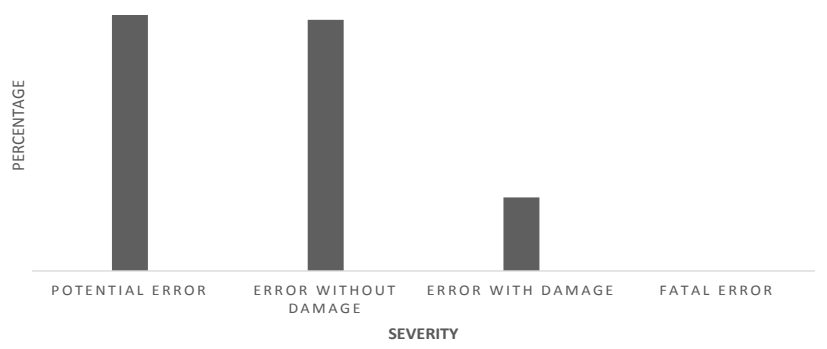

Fig. 2: Severity of medication errors

(6.3\%; Table 2). The severity of the medication errors is represented in fig. 2 , the category of error with damage represents $13 \%$ of the medication errors analysed, no fatal errors were reported during the progress of the study.

At the beginning of the 20th century, the development of scientific research was able to double the life expectancy through the use of antibiotics and vaccines. Now humankind is on the threshold of reaching an age of more than $100 \mathrm{y}$ with the use of biotech medicines, which have a greater therapeutic capacity than conventional drugs for the control of serious ailments such as cancer, heart conditions and diabetes. The tendency towards the use of this type of products made by genetic engineering from living cells is clear; however, it is also essential to guarantee the quality, safety and effectiveness of the molecules that make up such medications in clinical practice ${ }^{[36]}$.

Nowadays in Mexico, biotech medicines represent around $15 \%$ of the therapeutic arsenal available and its experimental and clinical research duplicates that of medications obtained by chemical synthesis worldwide. It is expected that the most used therapies in the coming years, including biosimilars, which face quality and safety challenges. Therefore, it is essential to establish the transcendence in the short and medium term of the consequences of their use, not only in terms of incidence, but also in its clinical consequences. The incidents derived from the use and handling of biotech medications has been investigated in order to generate the basis for their future prevention. They have been grouped into preventable, produced by an error (the objective of this study) and not preventable ADR. In the hospitals of our country, the detection and notification of ADR is more relevant, without giving medication errors their relevance due to the more serious consequences which can be avoided ${ }^{[37]}$. In the ENEAS study, the incidence of errors derived from health care that was found through the review of medical records is 1.4 per 100 patient-days, a lower figure than our results, which have combined the observational identification of each process of the biotech medicines system and the review of medical records. The difference may be due to the fact that the review of medical records underestimates the frequency of errors, and has not developed a reporting culture among the health personnel. In addition, there is no permanent reporting program, which is essential for identification of errors. The way to solve and systematize the analysis of incidents through the use of common language must be standardized. The internationally recognized NCCMERP criteria have been applied; however, they are not used universally. the overall results obtained showed an incidence rate 
of 3.6 errors per patient-day, a high figure compared to other authors' reports. Other investigations have yielded results between 0.15 to 0.24 errors per patient.

In hospital environments, medication errors are common; having an incidence rate 3 times higher in the paediatric population and potentially more harmful compared to the adult population ${ }^{[38]}$. Biotech medicines being large protein structures with immunogenic potential related to the process of obtaining, producing and nature of the protein, which constitutes a relevant problem in clinical practice in relation to its efficiency and safety. Antibodies can be developed by the patient throughout the therapy and their quantification is essential; however, this point is often omitted due to the fact that the test method is not available, or due to the ignorance of the medical staff that it does exist and must be quantified periodically. The use of medications in conditions other than those authorized in paediatric patients is a common practice perhaps due to the limited therapeutic options. The riskbenefit must be assessed, even when the patient has developed antibodies or presented an adverse reaction without discontinuing therapy, which would otherwise make clear classification and long term consequences difficult to assess. In the study by Bond et al. ${ }^{[39]}$, one in every 20.32 errors causes injury and $0.35 \%$ in observations made in paediatric patients; results obtained in this investigation showed that $13 \%$ of the errors have caused a detrimental effect in the paediatric population; however, the way in which these have been evaluated and identified makes the difference ${ }^{[40]}$. The errors not only transcend the patient's health, but also the hospitalization costs, slowing their improvement, not to mention the complaints or reclamations that may be generated, Bates et al. ${ }^{[41]}$. calculated that it takes $8 \mathrm{~min}$ to correct an error of omission and believed that the other medication errors take the same time.

In studies coordinated by the Spanish delegation of the Institute for Safe Medication Practices, it was mentioned that medication errors can motivate $4.7 \%$ of the income in medical services, with high costs for health systems. The research by Otero et al. found a total of 60 types of errors, $70 \%$ of these originated in the process of prescription and in a proportion of $28.3 \%$ had been originated in the follow-up of the pharmacological treatment ${ }^{[6]}$. The most frequent prescription errors were the prescription of medications in higher doses than recommended $(21.7 \%)$, the inappropriate selection of the medication $(15.0 \%)$ and the lack of prescription of a medication necessary to treat the underlying disease or to prevent and adverse effect.

November-December 2019

Indian Journal of Pharmaceutical Sciences

059
Errors occur frequently in the prescription, dispensing and administration of the medications; the most frequent are due to incorrect calculations of the dose, errors in the dilution and frequency of administration, even the poor and incomplete transcription of an indication, the incorrect wording and its illegibility. Some results on the incidence of prescription errors oscillate between 39 and $62.8 \%$ of the total ${ }^{[42]}$ and the present result stood at $29.5 \%$, which is well below the above-mentioned results.

The incidence of preparation errors shows an estimate of $37.93 \%{ }^{[43]}$, which is much higher compared to results of this investigation, the reason is due to ignorance of the incompatibility of solutions and the time in which the reconstitution can be stable, before moving on to the process of administration.

The direct observation applied in this part of the investigation is the best method to identify errors in the preparation, considering its high cost and that requires the previous training of the personnel ${ }^{[44]}$. Present results showed that $19.5 \%$ of administrations represent an error and are different from the observations of Barker et al. They represent $14.6 \%$ in which the time of administration represents $40 \%$ of cases; unlike the current study where it is rare and settles on the lack of knowledge in the rate of infusion ${ }^{[44]}$. It should be taken into account that administration errors are the most difficult to avoid due to the lack of constraints, except the patient, the consequences may be slight, the errors of the route or the medication may be serious; or in the worst case, omissions can harm the patient as a result of not receiving the medication they need.

It was possible to verify the limited knowledge and access to the information of the medicines in the different areas, the lack of updating of the medical consultation documents for the doctors and nurses, as well as the constant rotation of the resident medical staff and their incomplete preparation thus increasing the risk of making mistakes with this particular group of medications; there is a great disinformation about the type of ADR and the interactions with other medications, believing that these did not occur, therefore the review of interactions with other medications, solutions or foods is omitted; this has led to improper use, highlighting: prescription and preparation in non-compatible solutions, for topical, oral and mouth rinses, without complying with the specifications of preparation, infusion speed, transport and storage. This puts health professionals and paediatric patients/population at risk, representing a high cost in the hospital health system. 
The pharmaceutical forms for biotech medicines are mostly unsuitable for paediatric patients, dosing errors and preparation are frequent because it is preferable to administer a higher or lower dose in order not to waste medicines. Inaccurate frequency and time of administration are practices that are accentuated as the workload increases being the main cause, or due to delay in dispensing or lack of stock.

In Mexico, the real magnitude of the problem of medication errors is unknown, and consequently, there has been no awareness of its consequences on patient safety or on a population as vulnerable as the paediatric population, except for some groups such as hospital pharmacists. The causes of medication errors are highly complex, multifactorial, and multidisciplinary since they can affect several processes, therefore, the professionals involved in the therapeutic chain, hence the relevance of generating antecedents that serve to combat them. Errors can be combated through the design and implementation of interventions to improve the medication process.

This work has promoted the work in training programs, guidelines for use in the hospital environment and develop material focused on the importance of the proper use and management of biotech medicines. Further research and implementation of a standardized system of medication error definitions and outcomes is required. It would be relevant to generate data on interventions to reduce paediatric mortality that would support politicians and medical leaders in making decisions.

The limitations of the study were, this study was carried out in a high-specialty hospital, only in certain areas with a greater use of biotech medicines, this was due to the difficulty and the cost of extending it to other areas. The observations were not covered-up, which could influence the results of some stages, considering the Hawthorne effect, which consists of improving the activity of a worker when it is.

The difficulty to carry out exhaustive quality controls in the processes of use of biotech medicines was proven. Despite the difficulties presented, this study lays the foundations so that in the future other projects with a similar methodology can be developed and the results will serve to plan the interventions that can reduce the error.

\section{Financial interest and scholarship:}

We thank Consejo Nacional de Ciencia y Tecnología
(CONACYT, Mexico) for financial support via scholarship No.514878.

\section{REFERENCES}

1. Aranaz JM, Agra Y. La cultura de seguridad del paciente: del pasado al futuro en cuatro tiempos. Med Clin 2010;135:1-2.

2. Aranaz-Andrés JM, Aibar-Remón C, Limón-Ramírez R, Amarilla A, Restrepo FR, Urroz O, et al. Prevalence of adverse events in the hospitals of five Latin American countries: Results of the 'Iberoamerican study of adverse events' (IBEAS). BMJ Qual Saf 2011;20:1043-51.

3. Shojania KG, Duncan BW, McDonald KM, Wachter RM, Markowitz AJ. Making health care safer: a critical analysis of patient safety practices. Evid Rep Technol Assess 2001;(43):i$\mathrm{x}, 1-668$.

4. Tiernan S, Chambers R, Richardson K, Schembri K, Galea J, Williams I. Reducing risk in general practice. Aust Fam Physician 2015;44:323-26.

5. Strand JN. Reducing Medication Errors. JAMA2001;286:209192.

6. Otero MJ, Martin R, Robles MD, Codina C. Errores de medicación. Madrid: SCM, DL; 2002. p. 713-47.

7. Crommelin D, Bermejo $\mathrm{T}$, Marco $\mathrm{B}$, Jaak $\mathrm{D}$, Irene $\mathrm{K}$, Patrick R, et al. Pharmaceutical evaluation of biosimilars: important differences from generic low-molecular-weight pharmaceuticals. Eur J Hosp Pharm Sci 2005;11:11-17.

8. Zuñiga L, Calvo B. Biosimilars approval process. Regul Toxicol Pharmacol 2010;56:374-77.

9. Calvo B, Zúñiga L. Medicamentos Biotecnológicos: Requisitos Exigidos para el Desarrollo y Aprobación de Biosimilares Biological. Inf Tecnol 2010;21:125-32.

10. Kleinberg M, Mosdell KW. Current and future considerations for the new classes of biologicals. Am J Health Pharm 2004;61:695-708.

11. Tang L, Persky AM, Hochhaus G, Meibohm B. Pharmacokinetic aspects of biotechnology products. J Pharm Sci 2004;93:2184204.

12. Kessler M, Goldsmith D, Schellekens H. Immunogenicity of biopharmaceuticals. Nephrol Dial Transplant 2006;21:9-12.

13. Sharma B. Immunogenicity of therapeutic proteins. Part 1: Impact of product handling. Biotechnol Adv 2007;25:310-17.

14. Jasso-Gutiérrez L, Castellanos-Solis EC, Santos-Preciado JI. Costo de los medicamentos por grupo terapéutico y tipo en un hospital pediátrico de tercer nivel de atención. Bol Med Hosp Infant Mex 2007;64:349-61.

15. Kohn LT, Corrigan JM, Donaldson MS. To Err Is Human: Building a Safer Health System. Institute of Medicine (US) Committee on Quality of Health Care in America. Washington (DC): National Academies Press; 2000.

16. Payne CH, Smith CR, Newkirk LE, Hicks RW. Pediatric Medication Errors in the Postanesthesia Care Unit: Analysis of MEDMARX Data. AORN J 2007;85:731-40.

17. Kellett $P$, Gottwald $M$. Double-checking high-risk medications in acute settings: A safer process. Nurs Manage 2015;21:16-22.

18. Levett-Jones T, Bruce B. Critical Conversations for Patient Safety: An Essential Guide for Health Professionals. London, United Kingdom: Pearson; 2013.

19. Ohashi K, Dalleur O, Dykes PC, Bates DW. Benefits and Risks of Using Smart Pumps to Reduce Medication Error Rates: A Systematic Review. Drug Saf 2014;37:1011-20.

20. Acheampong F, Anto BP, Koffuor GA. Medication safety 
strategies in hospitals - A systematic review. Int J Risk Saf Med 2014;26:117-31.

21. Bullock S, Manias E. Fundamentals of Pharmacology. 7th ed. London, United Kingdom: Pearson Higher Education; 2013.

22. National Coordinating Council for Medication Error Reporting and Prevention [cited 14 June 2019]. Available from: https:// www.nccmerp.org/about-medication-errors.

23. Alvarez AA, Adelaida Solis Angli LSTC. Agenda Estadistica de calidad y seguridad. Ciudad de Mexico; 2015. Available from: www.pediatria.gob.mx.

24. Consejo de Salubridad General. Cuadro Básico y Catálogo de Medicamentos; 2016. Available from: http://www.csg.gob.mx/ descargas/pdf/priorizacion/cuadro-basico/med/catalogo/2016/ EDICION_2016_MEDICAMENTOS.pdf.

25. Wolters Kluwer Clinical Drug Information. Online Drug References, Clinical Drug Information [cited 16 June 2019]. Available from: https://www.wolterskluwercdi.com/drugreference/online/.

26. IBM WH. Micromedex, Drug Information Application History \& Evolution, IBM [cited 16 June 2019]. Available at https:// www.ibm.com/watson-health/learn/micromedex.

27. Wishart DS, Feunang YD, Guo AC, Lo EJ, Marcu A, Grant JR, et al. DrugBank 5.0: A major update to the DrugBank database for 2018. Nucleic Acids Res 2018;46:D1074-82.

28. Aranaz-Andres JM, Aibar-Remon C, Vitaller-Burillo J, Requena-Puche J, Terol-Garcia E, Kelley E, et al. Impact and preventability of adverse events in Spanish public hospitals: results of the Spanish National Study of Adverse Events (ENEAS). Int J Qual Heal Care 2009;21:408-14.

29. U.S. National Library of Medicine [cited 14 June 2019]. Available from https://www.nlm.nih.gov.

30. FIP-OMS. Directrices conjuntas FIP/OMD, Sobre buenas practicas de farmacia y estandares para la calidad de los servicios farmaceuticos. The Netherlands; 2012 [cited 16 June 2019]. Available from https://www.fip.org/www/uploads/ database_file.php?id=334\&table_id.

31. National Commission for the Protection of Human Subjects of Biomedical and Behavioral Research. The Belmont report ethical principles and guidelines for the protection of human subjects; 1978. Available from: https://www.hhs.gov/ohrp/ regulations-and-policy/belmont-report/read-the-belmontreport/index.html.

32. Valdespino Gómez JL GGM. Declaración de Helsinki, principios y valores bioéticos en juego en la investigación médica con seres humanos. Rev Colomb Bioética 2011;6:12444.

33. Salud S de. Reglamento de la Ley General de Salud en Materia de Investigación para la Salud. Mexico: Diario Oficial de la Federación; 2017.

34. Barroso C, Ferré R, Gallego V, Hernández Y, Wood M, Moreno E, et al. Pediatría. Farm Hosp 2006;11:1292-331.

35. Secretaria de Salud, Comisión federal contra riesgos sanitarios comisión permanente de la farmacopea de los estados unidos mexicanos. FEUM-Suplemento para establecimientos dedicados a la venta y suministro de medicamentos y demás insumos para la salud, sexta edición, Sexta. Ciudad de México; 2019 [cited 16 June 2019]. Available from: https://www. farmacopea.org.mx/publicaciones-detalle.php?m=3\&pid=4.

36. Kleinberg M, Mosdell KW. Current and future considerations for the new classes of biologicals. Am J Health Syst Pharm 2004;61:695-708.

37. Leape LL, Bates DW, Cullen DJ, Cooper J, Demonaco HJ, Gallivan T, et al. Systems Analysis of Adverse Drug Events. JAMA 1995;274:35-43.

38. Rinke ML, Bundy DG, Velasquez CA, Rao S, Zerhouni Y, Lobner K, et al. Interventions to Reduce Pediatric Medication Errors: A Systematic Review. Pediatrics 2014;134:338-60.

39. Bond CA, Raehl CL, Franke T. Medication Errors in United States Hospitals. Pharmacotherapy 2001;21:1023-36.

40. Raju TK, Thornton J, Kecskes S, Perry M, Feldman S. Medication errors in neonatal and paediatric intensive-care units. Lancet 1989;334:374-76.

41. Bates DW, Cullen DJ, Laird N, Petersen LA, Small SD, Servi $\mathrm{D}$, et al. Incidence of Adverse Drug Events and Potential Adverse Drug Events: Implications for Prevention. JAMA 1995;274:29-34.

42. Allen LaPointe NM, Jollis JG. Medication errors in hospitalized cardiovascular patients. Arch Intern Med 2003;163:1461-66.

43. Campino A, Santesteban E, Garcia M, Rueda M, Valls-I-Soler A. Errores en la preparación de fármacos intravenosos en una Unidad de Cuidados Intensivos Neonatal. Una potencial fuente de eventos adversos. An Pediatría 2013;79:21-25.

44. Barker KN, Flynn EA, Pepper GA. Observation method of detecting medication errors. Am J Heal Pharm 2002;59:231416. 